\title{
PEDRO ÁLVAREZ DE MIRANDA: MÁS QUE PALABRAS. BARCELONA, GALAXIA GUTENBERG, 2016 (272 PÁGS., ISBN: 978-84-16252-75-6)
}

\author{
David Prieto García-Seco \\ Universidad de Murcia \\ davidprieto@um.es
}

Más que palabras es un libro delicioso para aquellos que amamos la lengua española y su historia. Es manifiesto que esta obra nace de la pasión por la lengua, pero resulta evidente que este sentimiento no es, por sí solo, suficiente para alumbrar un libro como el que reseñamos si no se combina con otros ingredientes no tan usuales en el ámbito investigador. Sin duda, uno de estos ingredientes esenciales es el profundo conocimiento de nuestra lengua y de su léxico, conocimiento que en este caso procede principalmente, aunque, desde luego, no exclusivamente, de «la feliz concurrencia -afirma Manuel Seco en el prólogo- de diversas musas lingüísticas: unas, autóctonas o personales; otras, externas, nacidas de experiencias colectivas»; se alude, claro, a la sólida formación filológica que el autor, Pedro Álvarez de Miranda, cosechó a partir de la larga y meditada gestación del libro de 1992 titulado Palabras e ideas: el léxico de la Ilustración temprana en España (1680-1760) y durante los trece años en que participó en la elaboración del Diccionario histórico de la lengua española. Solo gracias a este singular bagaje se entiende la publicación de Más que palabras.

Componen el libro cuarenta y cinco ensayos monográficos, publicados la mayor parte de ellos entre 2009 y 2014 en la revista diaria Rinconete, que edita el Centro Virtual Cervantes, del Instituto Cervantes. Estos ensayos abordan distintas cuestiones atinentes a la lengua española, si bien, como se verá más abajo, es frecuente que se responda a preguntas cruciales en torno a una determinada palabra como cuándo, cómo y dónde apareció. Ni el monografismo aludido ni algunos de los títulos de los artículos, representados por unidades léxicas, deben inducir al error de pensar que tales disertaciones se centran exclusivamente en esta o aquella voz particular. Hay en todos los trabajos recogidos en este volumen un deseo de trascender los casos particulares estudiados - que, dicho sea de propósito, resultan paradigmáticos del fenómeno en cuestión- y alcanzar el rango de categoría. Se puede decir, por tanto, que cada trabajo se detiene especialmente en una o varias voces concretas, pero lo hace en la medida en que ello le permite al autor presentar los rasgos del fenómeno tratado y reflexionar en torno a él. De este modo, es cierto que se estudia monográficamente la voz espúreo (y, desde luego, espurio),

Para citar esta reseña / To cite this book review: Prieto García-Seco, David (2017). Reseña de Pedro Álvarez de Miranda: Más que Palabras. Barcelona, Galaxia Gutenberg, 2016 (272 Páginas). ELUA, 31: 363-372. doi:10.14198/ELUA2017.31.19

Enlace / Link: http://dx.doi.org/10.14198/ELUA2017.31.19 
pero no lo es menos que a partir de ella, en realidad, se nos está hablando particularmente de la ultracorrección y, en un plano más general, de los eventuales desajustes entre la norma y ciertos usos. El estudio sobre la voz guzpatarra aborda, entre otras, una cuestión muy importante del diccionario académico, como es la necesaria purga de voces innecesarias. El trabajo «¿Por qué cocodrilo y no cocreta?» se detiene en el estudio de dichos sustantivos, pero a partir de ellos y otras palabras (quebrar < crebar < lat. crepare; estupro/estrupo < lat. stuprum) se trata el fenómeno de la metátesis. El trabajo «Excursionista» ejemplifica magistralmente un caso de lo que Álvarez de Miranda llama creación inducida (o calco), esto es, una formación léxica que ocurre en una lengua con procedimientos propios de esa lengua pero propiciada o inducida por el modelo de otras lenguas que tienen previamente en su léxico el correspondiente cognado (inglés excursionist, francés excursionniste $>$ español excursionista). A la huella que un individuo puede dejar en su idioma se dedican los trabajos «Onomaturgia» y «Ultraísmo, ultraísta», y en cierto modo también «Maniqueo (o Un dato más sobre la influencia de Ortega en la lengua española)». Por su parte, «Michelín» es un trabajo que trata la lexicalización de elementos que no pertenecen al léxico común, como son las marcas comerciales. A partir de ejemplos como aspirina, casera 'gaseosa', chupachups, dónut, kleenex (o, acaso mejor, clínex), minipímer o támpax se explica en qué consiste este procedimiento de creación léxica, y, particularmente, se estudia el caso que da nombre común al ensayo: michelín 'pliegue de gordura que se forma en alguna parte del cuerpo, especialmente en la zona de la cintura'. Además de poner de relieve la singularidad semántica que posee en español este nombre respecto de lenguas como el inglés, el francés y el italiano, se rastrea y explica su interesante proceso de lexicalización. Y son muchos otros, en fin, los asuntos en torno a la lengua abordados en el libro.

Los estudios que recoge Más que palabras persiguen normalmente trazar el periplo vital de una palabra, pero en no pocas ocasiones esta palabra sugiere el estudio de otras. Es lo que sucede con el trabajo en torno al nacimiento y difusión de la voz café, incluidas varias de sus acepciones principales, pues al hilo de la exposición de la vida de café conviene también hablar de su familia léxica. Así, se atiende a cafetera 'recipiente para preparar o servir el café', cafetero 'encargado de un café', cafetería 'establecimiento donde se vende y toma café y otras consumiciones', cafetín, cafetal y cafeto. Y lo mismo ocurre, entre otros, con el estudio de la palabra excursionista, en el que se hace necesario primero trazar la trayectoria de excursión.

Antes de referirnos a la tipología tripartita de los escritos, querríamos aún resaltar otros rasgos destacables de esta obra. El más importante, sin duda, es el rigor filológico y científico de todos los ensayos, sustentado en el principio de documentación textual. Todo lo expuesto está fielmente basado en los usos idiomáticos constatados por el autor y constatables por el lector. Hay que decir que quizá alguien, acostumbrado a otro tipo de trabajos del profesor Álvarez de Miranda, más académicos, eche en falta una mayor precisión en la cita de los textos aducidos (ediciones, páginas, etc.); sin embargo, debe saberse que la obra Más que palabras no solo pretende llegar al iniciado en cuestiones de lengua, sino a un público mucho más amplio, un público culto, podría decirse, interesado por su lengua. Se explica así que el autor haya adoptado en sus escritos un tono divulgativo -veteado a veces con un sutil humor- que aconseja la supresión del aparato erudito, lo que no implica que no esté latente.

Elegida una voz, el autor examina detenidamente su comportamiento en sociedad, su vida, corta, larga o, a veces, inexistente, y todo ello, como decimos, avalado con usos idiomáticos constatados, con textos, como no puede ser de otro modo en el estudio histórico de una lengua. A cada paso el lector percibe y comprueba que las consideraciones que se 
hacen están firmemente basadas en la observación y análisis de numerosos textos obtenidos de diversas fuentes. Aunque no son los únicos manejados, muchos trabajos ponen de manifiesto que se ha acudido a los corpus académicos CORDE o CREA. Pero, como decimos, no son las únicas, y quien se dedica al estudio del léxico sabe, además, que no pueden ser las únicas. Álvarez de Miranda se sirve también del opimo material que le brindan distintas hemerotecas digitales, tal como muestra la cita de no pocos periódicos, y frecuenta los ficheros de la Academia, como se confiesa en los trabajos dedicados a los sustantivos guzpatarra (pág. 65) y cascarabito (pág. 124). Acude el autor, en fin, a cualquier fuente que le permita arrojar alguna luz sobre el objeto de estudio, incluidos, naturalmente, los diccionarios, que, en palabras de Álvarez de Miranda, son «verdaderos notarios del uso» y «constituyen por tanto, en su serie histórica, un material subsidiario, un complemento muy valioso de la indagación textual» (pág. 70). Sobre la valía de las fuentes lexicográficas para el estudio del léxico, pueden verse ejemplos ilustrativos en los artículos «Notarios del uso» y «Modisto».

Como consecuencia del apego a los textos, del «rendido sometimiento a las armas de la filología» (pág. 14), los escritos recogidos en Más que palabras presentan un marcado carácter descriptivo, y solo en alguno de ellos encontrará el lector ciertos apuntes normativos, como ocurre, y es pertinente que así se haga, con el incorrecto empleo «este aula», en el ensayo «Quedarse solo», o con el uso que Manuel Seco propuso llamar «infinitivo introductor», en el trabajo «Hablar como indios». No obstante, el autor reconoce que en algún caso -por ejemplo, en «¿La verdugo o la verduga?»- los textos considerados no permiten decantarse por uno u otro uso y, por tanto, alcanzar a partir de ellos alguna conclusión en el plano normativo. Esto último nos lleva a subrayar otros rasgos de las disertaciones contenidas en este volumen: el sentido común del autor, su sensatez - que se deja notar especialmente en los trabajos sobre actitudes lingüísticas, de los que más adelante diremos algo-y, por último, su honestidad. Es cierto que la pasión por la lengua lo empuja a descubrir las interioridades de las palabras estudiadas, a desentrañar y explicar su origen y su ulterior desenvolvimiento; sin embargo, en alguna ocasión -y hay que decir que son muy pocas- se ve obligado a rendirse ante una palabra cuyas pesquisas no terminan de desentrañar un enigma concreto. Es lo que sucede en «¿Se acuerdan de la guzpatarra?», artículo donde se siguen todas las pistas, se consultan todos los textos que contienen tal voz, pero, expuestas todas las indagaciones y exhibidos todos los datos disponibles, el investigador confiesa no tener, por ahora, un respuesta segura en torno al juego que otrora designaba tal palabra. Hay otros casos en los que se hace patente la honestidad del autor, vinculada con el irrenunciable rigor filológico, con el apego al dato. En la exposición de los motivos que hacen todavía preferible la forma espurio a espúreo se indica que tanto en inglés como en italiano se respeta, con los retoques necesarios, el latino spurǐus, y seguidamente, a pesar de que suponga cierta concesión a la postura adversa, se añade con respecto al italiano: «aunque hay algún muy raro ejemplo de spureo» (pág. 20). La decisión de no excluir un dato «incómodo»-que, lamentablemente, no todos los investigadores toman- se halla, repetimos, en otros trabajos contenidos en este libro. Otra divisa más de la singularísima categoría científica de su autor.

Si bien la mayoría de los ensayos tratan cuestiones léxicas (incluidas las fraseológicas), también figuran en la colección algunos que abordan cuestiones gramaticales y ortográficas. 
«Acatar rechistando» y «Diptongos ortográficos (a vueltas con guión y guion)» son estudios que discuten sendas decisiones ortográficas en torno a la acentuación tomadas en las dos últimas ortografías académicas, de 1999 y 2010. En el primero se cuestiona la conveniencia de «la desaparición obligatoria de la tilde en las formas verbales agudas que, llevándola cuando van solas (por terminar en vocal, $-n$ o $-s$ ), la conservaban al recibir un enclítico y ahora la pierden: antes de 1999 se escribía llevóse; ahora, llevose» (pág. 26). El segundo trabajo trata diversos aspectos prosódicos de las palabras en que ocurren secuencias vocálicas formadas por una vocal cerrada átona y una abierta generalmente tónica y reflexiona sobre la oportunidad de la decisión académica de considerar tales combinaciones «a efectos ortográficos» siempre diptongos, llamados precisamente en la Ortografia de 2010 «diptongos ortográficos». En ambos trabajos se acatan, como conviene muy mucho que se haga en materia ortográfica, las decisiones tomadas por la Real Academia Española, pero se acatan -como indica el primer título- rechistando, $\mathrm{y}$, en el caso del segundo, podríamos decir que a regañadientes, pues de acuerdo con la minuciosa argumentación del autor no fueron las mejores decisiones posibles. Hay un tercer trabajo que se interesa por cuestiones ortográficas: «La tilde en los demostrativos y en solo». La constatación de que a raíz de la publicación de la última edición de la Ortografía de la lengua española (2010) de la Académica se ha extendido la inexacta idea de que entre las palabras que ahora no llevan tilde y antes sí la llevaban se encuentran el adverbio solo y los demostrativos este, ese y aquel con función pronominal es el motivo que empuja a Álvarez de Miranda a dedicar unas líneas a desterrar de una vez por todas esta falsa y -digámoslo todo- facilona idea a la que ciegamente se abrazan no pocas personas. Para ello sugiere la lectura atenta de la normativa académica desde 1959 hasta nuestros días y le ofrece al lector unas consideraciones muy pertinentes en torno a los matices que sobre tales aspectos de acentuación contienen las obras ortográficas tratadas. De este modo, se explica que ni a partir de las normas de 1959 era obligatorio tildar tales palabras (salvo en los contadísimos casos de anfibología, donde era necesaria: Llamaron a éste cretino; Resolvió sólo dos problemas) ni, desde luego, lo era tras la publicación de la Ortografía de 1999. A pesar de que la última Ortografía (2010) «ha estrechado aún más el cerco a esos acentos» (pág. 242), en realidad los aspectos esenciales continúan igual. En resumen, se reafirma que no están en lo cierto aquellos que, evitando el esfuerzo de entender e incorporar a su escritura los matices de tales tratados ortográficos, se aferran a la simplista idea de que en relación con la tilde de los demostrativos y de solo ha habido un cambio drástico en 2010.

Son varios los trabajos que discuten temas gramaticales: «El género no marcado», «La desdemostrativización de un demostrativo (ese)», «Hablar como indios», «Quedarse solo», «LLa verdugo o la verduga?» y «El funcionamiento gramatical del verbo abdicar». En el ensayo «Quedarse solo» se explican las incorrecciones gramaticales que suponen secuencias como este aula y mucha mayor cantidad, la primera debida, como se sabe, a la falta de concordancia entre el sustantivo femenino con $a$ tónica inicial y el determinante masculino, y la segunda provocada también por una anómala aunque difundidísima concordancia entre el adverbio mucho y el sustantivo femenino posterior. «LLa verdugo o la verduga?» plantea la cuestión de cuál de estas dos formas es preferible. Para ello el autor hace algunas consideraciones morfológicas generales y establece tres grupos de los sustantivos que designan persona o ser animado y tienen la terminación -o. Hecha esta división, se pregunta a cuál de los tres grupos expuestos pertenece dicho sustantivo, cuestión que trata de contestar con diversa documentación textual. Como decíamos más arriba, los textos aducidos no permiten 
decantarse normativamente por una de las dos formas, pues se trata de «un sustantivo instalado en la vacilación» (pág. 225). En el trabajo titulado «El funcionamiento gramatical del verbo abdicar» se explica minuciosamente que el uso que de dicho verbo se hizo en un trascendente comunicado del rey Juan Carlos («He decidido poner fin a mi reinado y abdicar la Corona de España) es «gramaticalmente irreprochable», pese a que alguien haya afirmado que el pasaje en cuestión «sonó mal» y resulta «anómalo».

Dada la especialización del autor, en Más que palabras abundan, naturalmente, los trabajos sobre el léxico español. Ya se han mencionado algunas de las cuestiones léxicas tratadas en este libro; veamos a continuación otros asuntos a los que también se presta atención. En ciertos artículos se pasa revista a la codificación lexicográfica que presentan ciertas unidades en los diccionarios del español, y se mide el grado de acierto de tal codificación. En el artículo «De estampida, de estampía» se constata que la forma primigenia de la locución fue de estampida y solo posteriormente, en el ámbito taurino, se produjo «la pérdida de la $-d$-, por el difuso andalucismo, o si se prefiere mero popularismo, que es consustancial a tales medios» (pág. 184). Por tanto, el trabajo denuncia que, mientras que el diccionario de la Academia (2001) recoge en la entrada estampía la construcción de estampía, no incluya sin embargo la forma equivalente de estampida.

Algunos de los trabajos atienden, podría decirse, a lo que Kurt Baldinger llamó en un estudio fundamental «miserias de la filología», es decir, describen el origen espurio de una palabra, que en realidad es una mera errata. A este tipo de ensayos pertenece, por ejemplo, «Estugafotulés / estugofotulés, o El teléfono escacharrado», donde se lleva a cabo la crónica de una errata y sus «variantes» posteriores, o el trabajo en el que se describe la divertida suerte que corrió la voz fantasma acudia, primero, en la lexicografía francesa de los siglos XVII al XIX y, a partir de ella, en algunos diccionarios españoles monolingües (incluido el Diccionario castellano de Terreros) y bilingües hispano-franceses. También nos habla de fantasmas léxicos el trabajo «Chebrón o chevrón, no cheurón». Otros trabajos describen las curiosas vicisitudes lexicográficas de algunas voces, como sucedió con el sustantivo antofagasta, llamativa forma festiva raramente empleada en el siglo XX y cuya anunciada inclusión en el diccionario común de la Academia estuvo «a punto de desencadenar un conflicto diplomático» (pág. 73).

Por otra parte, encontramos ensayos sobre voces del ámbito popular o rural, como el dedicado al andalucismo oriental cascarabito o el trabajo en torno al sustantivo biruji. En este último se atiende a sus múltiples variantes, entre las que destacan las fonéticas biruji, biruje; la morfológica birujis y la prosódica biruji. Podemos añadir nosotros otra variante fonética popular, con adición de -r-: birurji, difícil de documentar en textos formales, pero que puede encontrarse en textos informales - por ello de gran valor para el filólogo- como son los foros virtuales, los chats y otro tipo de páginas de internet. Ahí va un puñado de estos textos, en que dicha variante fonética también presenta, como cabía esperar, inestabilidad gráfica $(b / v-g / j)$ :

\section{Birurgi}

Esta mañana hacía un birurgi en la meseta que se pelaban los dedos. (Foro-Ciudad.com, 8 de septiembre de 2008; en línea: http://www.foro-ciudad.com/caceres/casares-de-lashurdes/mensaje-1413489.html; consulta de esta página y de las que siguen: 21 de mayo de 2017).

Termino de llegar a casa y no veas cómo se agradece entrar al hogar, dulce hogar, con la calefacción encendida, ya que en la calle hace un birurgi, ufff. (Verpueblos.com, 9 de noviembre de 2009; en línea: https://www.verpueblos.com/usuario/44621/mensajes/6266/). 
Birurji

He llegado a comprar protectores para "obstruir" el paso del aire, y aun así no veas cómo se nota el birurji al entra en casa. (NuevosVecinos.com, 29 de enero de 2008; en línea: https://www.nuevosvecinos.com/restonplaza/1808331-aislante-de-las-placas-negras).

(Mi cazadora es la caña) el lunes me voy a por el cuerooooooooooooooo porque en cueros ya iba y empieza a hacer birurji. (Motos.net, 17 de octubre de 2008; en línea: http://debates. motos.coches.net/showthread.php?187167-\%BFD\%F3nde-comprar-en-Asturias/page6).

\section{Virurgi}

Yo tengo una [vitrocerámica] mixta de gas natural e inducción, no va mal, pero tengo la cocina taladrada de rejillas de ventilación y ya estoy cansada, menudo virurgi entra en invierno. (Forumfree.it, 16 de octubre de 2007; en línea: http://gatosrenegados.forumfree. it $/ ? \mathrm{t}=20160231 \& \mathrm{st}=75$ ).

Otra cosa es el virurgi que pega, mucho frío y mucho calor. (Buscaopiniones.com, 30 de marzo de 2008; en línea: https://www.buscaoposiciones.com/foro/Oposiciones-Correos-yTelegrafos-fmen-4-3202383.htm).

Virurji

No hay que estar bien de la azotea para comer las doce uvas en la plaza, con el virurji que debe hacer. (Foro-Ciudad.com, 18 de agosto de 2008; en línea: http://www.foro-ciudad. $\mathrm{com} /$ caceres/casares-de-las-hurdes/mensaje-1463053.html).

Voy a cerrar las ventanas de la casa, que entra virurji. (Facilísimo.com, 14 de diciembre de 2010; en línea: http://forobebes.facilisimo.com/foros/embarazo/buscar-embarazoix_267806_130.html).

Más que palabras recoge, asimismo, cinco trabajos dedicados a diversos aspectos de los fraseologismos: «Será por reyes», «Un dicho y su porqué (con una breve consideración sobre el "léxico familiar")», «Aceptar pulpo como animal de compañia», «Pasarlas moradas» y «De estampida, de estampía». En «Aceptar pulpo como animal de compañía» se trata la cuestión del origen de los modismos. Como se sabe, no siempre nos es dado ofrecer una explicación satisfactoria al porqué de determinados fraseologismos. Es más, lamentablemente, es frecuente que no podamos darla, como sucede con la expresión noche toledana. «La dificultad para explicar el porqué de un dicho -afirma Álvarez de Miranda- es directamente proporcional al tiempo transcurrido desde que nació -y los hay antiquísimos-, pues durante dicho tiempo se borran las pistas y suele perderse la conciencia del origen» (pág. 144). Partiendo de este hecho, en este trabajo se ofrece una detallada explicación del neologismo fraseológico aceptar pulpo como animal de compañía y se muestra, con una ilustrativa selección de textos, el proceso de fraseologización que, finalmente, dio lugar a esta locución verbal.

Es realmente interesante el trabajo consagrado, como el anterior, a desentrañar el origen de la locución verbal pasarlas moradas. Antes de adoptar la forma que hoy todos conocemos, originariamente la construcción era pasar las moradas, con el artículo las, no un pronombre enclítico. Se atiende, desde luego, a la cronología de esta expresión, pero resulta especialmente llamativo comprobar que las explicaciones de su origen que habían dado dos estudiosos no eran las más convincentes. En sus Más de 21.000 refranes castellanos (1926) Rodríguez Marín comentaba que «en Andalucía llaman pasar las moradas a pasar muchos trabajos, por referencia a las pintas del sarampión» (pág. 171). Por su parte, en 1972 Lázaro Carreter explicaba en Lengua española: historia, teoría y práctica lo siguiente sobre pasar las moradas: «locución que alude a las 
moradas que, según el famoso libro de Santa Teresa, debe pasar el alma para unirse con Dios» (pág. 167). Mediante la exposición de una rica documentación textual, el profesor Álvarez de Miranda muestra que la construcción (sobre todo en su forma sincopada pasar las morás) tiene su nacimiento en Andalucía, concretamente en Sevilla, y demuestra que el origen de la construcción pasar las morás, abreviación de pasar las morás y las partías, se refiere a las aceitunas; se trata, en fin, de una «alusión a un hábito alimentario al que no tenían más remedio que acudir quienes más penalidades sufrían para procurarse el diario sustento» (pág. 171).

«Nadie es purista», «No hay que alarmarse» y «Omnia nova... non placent» son trabajos relacionados al ofrecerse en ellos reflexiones en torno a las actitudes de la gente ante su lengua. En el primero se hace un repaso histórico de la actitud lingüística llamada «purismo» (incluyendo el estudio del nacimiento de las palabras purista y purismo) con el propósito, bastante sensato, de quitar hierro al aparente mal de la novedad lingüística, puesto que al fin y al cabo esta es connatural a las lenguas: «las únicas lenguas que no evolucionan son las lenguas muertas» (pág. 191). Asimismo, se hace un repaso de algunos de los trabajos en los que se enarbola la bandera del purismo, entre los que destaca El dardo en la palabra (1997), de Fernando Lázaro Carreter, obra que, sorprendentemente, aún hoy siguen utilizando en sus clases algunos profesores de lengua, sin ser conscientes de que muchos de los usos criticados ya llevan años perfectamente instalados en el habla culta. En «No hay que alarmarse» se trata «la inquietud que a muchos producen los hábitos gráficos que ha traído consigo el uso de la lengua en los mensajes de texto desde teléfonos móviles, en los chats y en determinadas redes sociales» (pág. 205). Resulta muy oportuna la comparación que establece Álvarez de Miranda entre esa inquietud y la que produjo, con tintes realmente catastrofistas, la utilización del telégrafo, sistema de comunicación que, junto con otras novedades de la filosofía y la política, «muestran -en dramáticas palabras de don José de Selgas y Carrascoparticular empeño en destruir el gallardo monumento de nuestra lengua patria» (pág. 207). En este trabajo y en el anterior Álvarez de Miranda ofrece a tales actitudes de rechazo y de alarmismo el mejor remedio posible, que no es otro que la mirada histórica, es decir, el conocimiento, y la impagable enseñanza, que nos ofrece la historia de la lengua, con la que se relativizan las cosas e incluso en ocasiones se consigue desdramatizarlas. «Omnia nova... non placent» plantea de nuevo el porqué del rechazo que muchos hablantes presentan ante la novedad léxica. Para ejemplificar este rechazo y reflexionar sobre él se estudian los casos particulares de resiliencia y escrache, sustantivos que, como tantos otros neologismos (el segundo de ellos es, concretamente, un caso de «préstamo interno», del español de Argentina y Uruguay al de España), han recibido a partir de ese rechazo descalificaciones «de orden estético»: esta palabra o aquella otra, sentidas como nuevas, son «feas», «horrorosas», «espantosas», etc. Ante esta inexplicable actitud misoneísta de los hablantes, frecuentemente sugerida por cuestiones puramente fónicas, Álvarez de Miranda propone algunas consideraciones sobre la naturaleza fónica de las palabras (simplemente, «combinaciones arbitrarias, podríamos decir incluso aleatorias, de los fonemas», pág. 238) y sobre la oportunidad de que una lengua acoja de otra palabras si estas resultan necesarias.

A las actitudes mencionadas en los tres trabajos anteriores -que podrían aunarse bajo el misoneísmo al que nos hemos referido- se opone la preservación de la unidad del idioma, necesario empeño del que se habla en «Panhispanismo: un congreso de 1963». Este trabajo recuerda que el concepto que acoge el hoy muy empleado adjetivo panhispánico y, por ende, la actitud unificadora de aquellos que se refieren a la lengua española en su dimen- 
sión internacional no son en absoluto novedades propias de los últimos años, sino que el panhispanismo ya ocupó un lugar central en la «Asamblea de Filología del I Congreso de instituciones hispánicas», convocada por el Instituto de Cultura Hispánica y celebrada en el mes de junio de 1963. Principalmente, deben subrayarse las conclusiones de los trabajos de la comisión dedicada a la «Unidad del español», redactadas por Eugenio Coseriu, pues se trata de un texto excelente que, entre otros, se podría presentar a los alumnos de asignaturas dedicadas al español normativo para mostrar uno de los escritos que sentaron las bases de la actual «política lingüística panhispánica», tendente a la unificación de la lengua española, pero llevada a cabo, dice dicho programático texto, «con un absoluto respeto a las variedades nacionales tal como las usan los hablantes cultos y teniendo en cuenta que la unidad idiomática no es incompatible con la pluralidad de normas básicas, fonéticas y de otro tipo que caracterizan el habla ejemplar y prestigiosa de cada ámbito hispánico» (pág. 203).

Frente a la popular y melancólica idea de que el léxico se empobrece, uno de los trabajos («¿Empobrecimiento?») muestra que lo que sucede, precisamente, es lo contrario, que el léxico de una lengua tiende a su enriquecimiento: «El creciente espesor de los conocimientos humanos, la sutilización y matización del pensamiento, el desarrollo material e intelectual, la mera proliferación sinonímica no imprescindible, incrementan sin cesar un arsenal de piezas denominativas y conceptuales en el que sin duda son más los registros de entrada que los de salida» (págs. 246-247). Viene al caso, pues, tratar en este trabajo, con ejemplos y observaciones muy oportunos, el fenómeno de la «pérdida» o «muerte» léxica, los arcaísmos y la falsa creencia de que la desaparición del referente trae consigo la pérdida de la palabra que lo designa. Con el ensayo anterior se relaciona otro llamado «Reciclajes y resurrecciones léxicas», donde se habla de la recuperación por parte de una voz de los niveles de frecuencia de uso que tuvo y que perdió. Se ejemplifica el fenómeno del reciclaje léxico con dos casos paradigmáticos del español: azafata 'asistente de vuelo' y deporte. En cuanto a las resurrecciones, palabras que habían muerto y que el uso, fundamentalmente por una cuestión de necesidad real designativa, vuelve a insuflarles nueva vida, se muestra el caso de gobernanza, empleada en el siglo XV, con una fugaz reaparición en el XVII, y resucitada a mediados de los años ochenta del siglo pasado.

Llegados a este punto, debemos hacer algunas consideraciones finales. La primera es que la nueva edición del Diccionario de la lengua española (2014) de la Academia ha prestado oídos a las razones esgrimidas y bien documentadas de varios de los estudios contenidos en Más que palabras y ha hecho suyas algunas de sus propuestas, como sucede, por ejemplo, con la concerniente a la forma de estampida, registraba bajo la voz estampida con la siguiente codificación: «loc. adv. Repentinamente y con precipitación impetuosa. Salir, marcharse de estampida». En cuanto al artículo estampía, también es sensible su mejoría gracias al estudio correspondiente de este libro. Mientras que antes $(D R A E, 2001)$ en dicho artículo se recogían inadecuadamente las supuestas locuciones verbales «embestir, partir, o salir, de [estampía]», con la también claramente inoportuna definición «Hacerlo de repente, sin preparación ni anuncio alguno», ahora (DLE, 2014) ha pasado a consignar la locución adverbial de estampía, con remisión a la forma plena y con un ejemplo ligeramente distinto, pues incluye, dado que es relevante esta información de «colocación», el verbo escapar: «Salir, marcharse, escapar 
de estampía». Por otra parte, el estudio dedicado a la voz guzpatarra constata la rareza de esta palabra (en realidad, guzpátara) y, en consecuencia, se concluye que «debe desaparecer del diccionario común» (pág. 69). Pues bien, puede observarse que, en efecto, dicho trabajo -publicado por primera vez en 2011- ha conseguido el fin perseguido, puesto que tal voz ha sido suprimida en la edición 23. ${ }^{a}$ del diccionario académico (2014). Que otras propuestas hechas en estos trabajos han sido igualmente acogidas en la última edición del repertorio académico podrá comprobarlo el lector, entre otros trabajos, en «Chebrón o chevrón, no cheurón».

Querríamos también resaltar un aspecto que no pasará inadvertido al lector atento de Más que palabras, y es que de sus páginas se desprenden para quien desee penetrar en el fascinante y enriquecedor mundo de la vida de las palabras valiosísimas clases magistrales sobre cómo acometer el estudio de unidades léxicas. Se advierte que por nuestros pecados -que principalmente pondrían reducirse a uno: no haber sido capaces de culminar la obra lexicográfica más importante de nuestro idioma, el Diccionario histórico de la lengua española (1960-1996)para realizar un estudio léxico se hace necesaria la consulta de multitud de diccionarios, entre los que sobresale la primera obra académica, el celebrado Diccionario de autoridades (17261739). Son muchos los artículos en los que se manifiesta la excelencia lexicográfica de esta obra, su modernidad y los servicios que incluso hoy día, al cabo de tres siglos de su alumbramiento, sigue prestando principalmente a los estudios léxicos de corte diacrónico (cfr. págs. 36-37, 71-72, 101, 130-131, etc.). Son otros dos los hitos lexicográficos a los que Álvarez de Miranda recurre con alguna frecuencia, sin duda por su extraordinaria calidad, el mencionado Diccionario histórico y el Diccionario del español actual, dirigido por Manuel Seco (1. a ed., 1999, y 2. ${ }^{\text {a }}$ ed., 2011). Asimismo, hay observaciones sobre otros diccionarios y repertorios lexicográficos que también suponen un auxilio valioso para el investigador del léxico. Estos diccionarios, sobre todo cuando se apartan del mero plagio del de la Academia, contienen informaciones relevantes que, muchas veces, complementan las recogidas en el diccionario usual. Sucede con el Diccionario nacional (1846-1847) de Joaquín Ramón Domínguez, que aporta al investigador algunas explicaciones metalingüísticas significativas, como podrá comprobarse, por ejemplo, a propósito de las voces excursión (págs. 107-108), ultraísmo (pág. 114) o ensimismarse (págs. 156 y 160). También se dan pistas, en fin, de otras obras lexicográficas aprovechables hoy día para el historiador del léxico, como es el Rebusco de voces castizas (1907) del P. Mir y Noguera o el Diccionario de uso del español (1966-1967) de María Moliner.

Está fuera de toda duda que es insoslayable el uso conjunto de fuentes primarias (textos) y fuentes secundarias (obras lexicográficas), pero este libro nos aconseja que tanto unas como otras deben manejarse con la debida cautela. El trabajo «Una errata funesta» es un ejemplo excelente de los «efectos devastadores» que puede acarrear la mala lectura de un texto, atañedero en este caso nada menos que a la difundida expresión buen gusto, atribuida a la reina Isabel la Católica. Similar precaución hay que tener con los diccionarios. Aunque el autor conoce, y conoce muy bien, las virtudes de las múltiples ediciones del diccionario usual de la Académica, heredadas en gran medida del Diccionario de autoridades, no se le escapan las flaquezas de aquel diccionario, y en sus trabajos siempre se ha mostrado muy crítico con él. Se ha dicho que algunas palabras son prescindibles en esta obra, como el aludido caso de guzpatarra, pero también sucede, desde luego, lo contrario: muchas otras palabras y acepciones faltan en el diccionario de la Academia. Así lo pone de manifiesto el artículo «Dudas onomasiológicas: coquilla y bragueta» (publicado por primera vez en 2011), donde se denuncia la ausencia en el diccionario académico de la palabra coquilla y 
del significado 'cobertura ostensible de las partes pudendas del varón añadida a las calzas o calzones' de bragueta, ambos - palabra y acepción- recogidos ya en el DLE (2014).

A partir de la afirmación que tiene lugar en 1611. Revista de Historia de la Traducción de que en el año 1611 se incorporó al español la voz traductor, en el ensayo «Peras al olmo» se habla de la vigencia del Diccionario crítico-etimológico y, unida a ella, de la prudencia con que debe manejarse la obra de Corominas. El artículo concluye con una nota precautoria que, lamentablemente, sigue siendo oportuna hoy día: «debemos encarecerles, a ellos [los responsables de dicha revista] y a otros muchos, que no pidan al venerable, añoso olmo plantado por don Joan Corominas las peras que no puede darles» (pág. 53). Otro trabajo («Excursionista») también previene al consultante sobre los usos no previstos en la obra de Corominas. Al margen de la valía histórica de su obra, que está fuera de toda duda, lo que se pretende de nuevo es poner de manifiesto que hay que tener mucha precaución al utilizar el benemérito Diccionario crítico-etimológico, que no es, huelga decirlo, un diccionario histórico.

Se obtienen, en fin, otras impagables enseñanzas que, partiendo de las voces estudiadas, van más allá de ellas. Mientras que los hablantes instruidos se decantaron por la forma croqueta en detrimento de cocreta, es decir, triunfó la forma etimológica (francés croquette), no sucedió lo mismo con la palabra cocodrilo en español (ni en italiano: coccodrillo), pues sus hablantes -a diferencia del francés o el inglés, que mantuvieron la forma etimológica (latín crocodilus)prefirieron la variante con mutación fonética. De este modo, en «¿Por qué cocodrilo y no cocreta?» se muestra con exquisita elegancia «que iluminar los problemas desde la historia de la lengua debería llevar a la convicción de que no merece la pena rasgarse las vestiduras por casi nada» (pág. 85). Del artículo «Modisto» se desprende la misma enseñanza, y, además, hay que añadir otra que no conviene olvidar, y es que, en cuestiones de lengua, el pueblo es soberano. La historia de la palabra modisto es un buen ejemplo de ello. Habiéndose generalizado la voz modista en español durante el siglo XVIII, a mediados de la centuria siguiente comenzó a utilizarse el rarísimo modisto. «La novedad - afirma Álvarez de Miranda- implicaba cierta aureola de prestigio elegante que situaba a los modistos, a menudo distinguidos por más o menos vagas conexiones parisinas, por encima de la simple modista [...]. Un cierto clasismo alienta tras la insólita novedad léxico-morfológica» (pág. 103). Pues bien, pese a que la Academia, junto con otros normativistas y críticos del lenguaje, rechazó el rarísimo masculino modisto, los hablantes, desoyendo las recomendaciones de la corporación, se decantaron decididamente por él.

Las enseñanzas a que acabamos de referirnos y los rasgos de la obra aludidos al principio (sobre todo, el hecho de pasar de lo aparentemente anecdótico a la categoría) hacen de esta obra un libro excepcional, del que sabrán gozar todos aquellos que acometan su lectura. A nadie se le oculta que, dada la extraordinaria reunión de tales características, estemos ante un utilísimo manual para los profesores de lengua de Enseñanza Secundaria, incluso para los de Educación Superior, que deseen proporcionar a sus alumnos un acercamiento atractivo y riguroso a los fenómenos lingüísticos tratados. Sin duda alguna, las palabras -y esta obra nos lo ilustra en cada página- no solo son palabras, unidades puramente fónicas, sino que son más bien una suerte de baúles, de distintos tamaños, que contienen merced al discurrir del tiempo que han vivido una acumulación de sentimientos, de pensamientos... Haciendo nuestras las palabras con que Seco concluye su prólogo, Más que palabras «nos lleva a reflexionar con provecho sobre lo mucho que puede esconderse detrás de cada palabra, de cada frase que sale de nuestros labios o recogen nuestros oídos. Eso significa enriquecer nuestra mente. Lo mejor que podemos pedir a un libro» (pág. 12). 